\title{
Erratum
}

\section{Erratum to "Distribution of Seven N-Nitrosamines in Food" [Toxicol. Res. 31 (2015) 279-298]}

\author{
Jong-eun Park', Jung-eun Seo ${ }^{1}$, Jee-yeon Lee ${ }^{2}$ and Hoonjeong Kwon ${ }^{1,3}$ \\ ${ }^{1}$ Department of Food and Nutrition, Seoul National University, Seoul, Korea \\ ${ }^{2}$ Bureau of Health Industry Policy, Korea Health Industry Development Institute, Cheongju, Korea \\ ${ }^{3}$ Research Institute of Human Ecology, Seoul National University, Seoul, Korea
}

Author wanted to change the acknowledgement stating the funding source from "This study was supported by a grant (13162KFDA046) from Ministry of Food and Drug Safety in 2013-4." to "This study was supported by a grant (13162KFDA049) from Ministry of Food and Drug Safety in 2013-4."

\footnotetext{
Correspondence to: Hoonjeong Kwon, Research Institute of Human Ecology, Seoul National University, 1 Gwanak-ro, Gwanakgu, Seoul 151-742, Korea

E-mail: hjkwon@snu.ac.kr
}

DOI of original article: http://dx.doi.org/10.5487/TR.2015.31.3.279
This is an Open-Access article distributed under the terms of the Creative Commons Attribution Non-Commercial License (http:// creativecommons.org/licenses/by-nc/3.0) which permits unrestricted non-commercial use, distribution, and reproduction in any medium, provided the original work is properly cited. 